\title{
Pathology of hyperextension injuries of the cervical spine
}

\author{
H Kinoshita MD
}

Director, Kosei Hospital, Hiroshima, Japan.

\begin{abstract}
Autopsies were performed between 1957 and 1987 on 31 patients with traumatic spinal cord injuries. Among these there were nine patients with hypertension injuries to the cervical spine composed of four patients with hyperextension injuries to the arthritic spine, three patients with hyperextension injuries to the rigid cervical spine, one patient with a self reduced posterior subluxation, and one patient with a hyperextension fracture-dislocation. The sex, age, clinical course, bone injuries revealed by roentgenograms, level and grade of neurological deficits, survival time, and findings of postmortem studies of those nine patients with hypertension injuries are presented in Table I. The methods employed in this study were the same as those that were described in my report on the pathology of cervical intervertebral disc injuries. ${ }^{1}$ This paper illustrates the pathological features of six of these cases and discusses the mechanism of the spinal cord lesions in various types of injuries.
\end{abstract}

Keywords: pathology of spinal cord injuries; cervical spine; hyperextension injuries.

\section{Case reports}

Case 1

A 75 year old man was admitted to our hospital after suffering facial injuries in a traffic accident. The left paraorbital haematoma suggested an extension mechanism. He had immediate bilateral numbness of the upper and lower extremities and paresis below $\mathrm{C} 4$, and incontinence of urine and faeces. The neurological deficit progressively deteriorated and complete paralysis developed 4 days later. He died on the 21 st day after injury.

The roentgenograms showed a slight degree of spondylosis with no bone injury. Autopsy revealed rupture of the intervertebral discs at the C3-4, C4-5, C5-6, and C6-7 interspaces. The posterior ligament complex was not ruptured and the spine was stable on anteflexion.

Spinal cord atrophy extended the whole length of the cervical spine together with a few small areas of focal softening, and necrosis was observed (Fig 1).

Correspondence: H Kinoshita MD. 86-2 Ichiida, Kurose-cho, Kamo-gun, Hiroshima-ken 724-06, Japan.
Case 3

A 73 year old man was struck by a car and sustained a bruise on the forehead. He had immediate complete motor paralysis below C6. Position sense was preserved and he could tell when he wanted to urinate.

The roentgenograms showed moderate cervical spondylosis deformans with no bone injury.

His condition steadily deteriorated with blood urea nitrogen level exceeding $100 \mathrm{mg} / \mathrm{dl}$. He died from renal failure on the 27 th day after the injury.

Postmortem examination showed ruptures of the anterior longitudinal ligament at the $\mathrm{C} 4-5$, C5-6, and C6-7 interspaces, extending through the intervertebral disc to the intact posterior longitudinal ligament. Extreme hyperextension of the spine was possible at the level of the injuries but it was stable on anteflexion. No intervertebral disc protrusion into the spinal canal was noted when vertical compression was applied to the spinal column (Fig 2a). The spinal cord was swollen between $\mathrm{C} 3$ and $\mathrm{C} 6$ vertebrae. Vacuolations were observed bilaterally in the lateral tract at the $\mathrm{C} 3,4,5$ vertebral levels (Fig 2b) together with disappearance of neurocytes in the grey matter and necrosis in the lateral tract on both sides and in the 


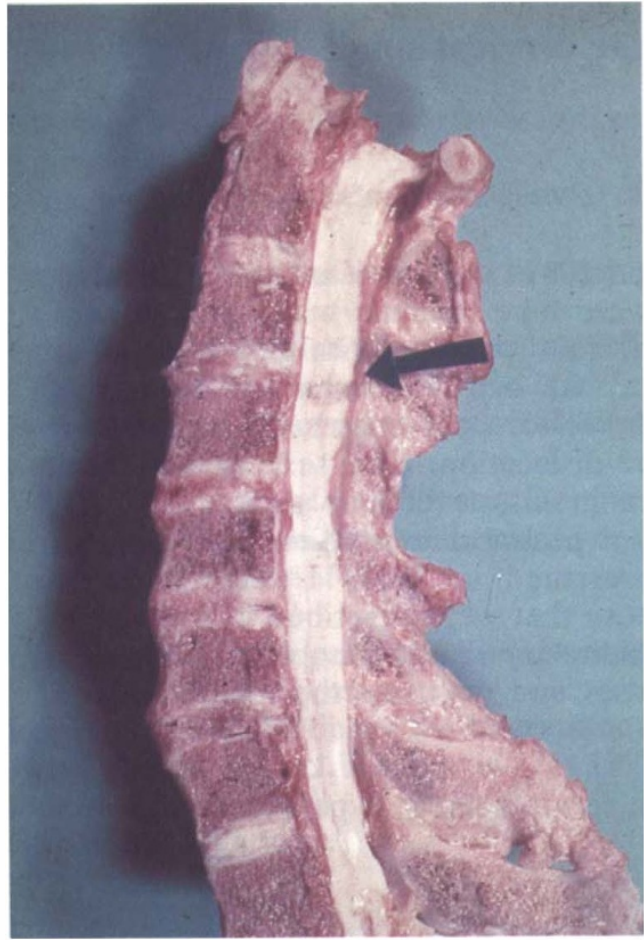

Figure 1 Multiple intervertebral disc injuries, atrophy of the spinal cord with multiple small lesions, intact posterior ligament complex are shown.

anterior tract on the right side at the level of C4-5 intervertebral space (Fig 2c).

\section{Case 4}

A 64 year old man fell from a height of $2.5 \mathrm{~m}$ and struck himself on the face. The patient immediately developed complete motor paralysis below C5 and only tactile sensation was preserved to both thighs. His condition progressively deteriorated and he died 26 days later of pneumonia.

Roentgenograms showed moderate osteoarthritic changes in the cervical spine with ossification of the anterior longitudinal ligaments at the C4-5 and C5-6 interspaces. There was no bone injury to be seen in the roentgenograms except for a fracture of an osteophyte at the anterior lower margin of C6 vertebra (Fig 3a).

Autopsy revealed that the anterior longitudinal ligaments and the intervertebral discs were ruptured at the C3-4, C4-5, and C5-6 interveretebral spaces. The spinal cord was remarkably swollen between C 3 and C6 vertebrae with small focal softening in the central portion of the spinal cord (Fig $3 b$ ).

\section{Case 7}

A 77 year old man fell onto his face from a height of $4 \mathrm{~m}$. He developed immediate complete tetraplegia below C5. There was no change in the neurological findings until his death 9 days after injury.

Roentgenograms showed extensive hypertrophic changes with osseous fusion of $\mathrm{C} 5$ and C6 vertebrae but no evidence of recent injury.

Autopsy revealed rupture of the anterior longitudinal ligament between $\mathrm{C} 3$ and $\mathrm{C} 4$ vertebrae. The rupture extended through the intervertebral disc to the intact posterior longitudinal ligament. Excessive hyperextension of the spine was possible at the level of injury, but there was no dislocation of the articular process. Ossification in the lower cervical spine accounted for localisation of the violence to the upper vertebrae and the rupture occurred immediately above the ossified region. The spinal cord was extremely swollen to fill up the spinal canal. A small cavity containing a blood clot was found in the central portion of the spinal cord (Fig 4).

\section{Case 8}

A 36 year old man while intoxicated with alcohol quarrelled with some men and was thrown into a river, striking his forehead against the river bed. He developed immediate complete paralysis below C5 and died 6 days after the injury.

Roentgenograms obtained at the time of initial examination showed no traumatic abnormality (Fig 5a).

Forensic autopsy revealed that the cause of death was respiratory failure due to posterior dislocation of $\mathrm{C} 3$ on $\mathrm{C} 4$ vertebrae and severe spinal cord contusion. The spinal column was torn by rupture of the anterior longitudinal ligament and the intervertebral disc between $\mathrm{C} 3$ and $\mathrm{C} 4$ vertebrae. The upper segment of the spinal column with the intact posterior longitudinal ligament could be displaced backwards on the lower segment with the posterior longitudinal ligament being lifted from the posterior surface of the $\mathrm{C} 4$ vertebra. At this point, there was a severe contusion of the spinal cord extending upward for $3 \mathrm{~cm}$ with haemorrhagic necrosis (Fig 5b). The displacement could be easily replaced and it tended to remain in the replaced position (Fig 5c). There is little doubt 
a

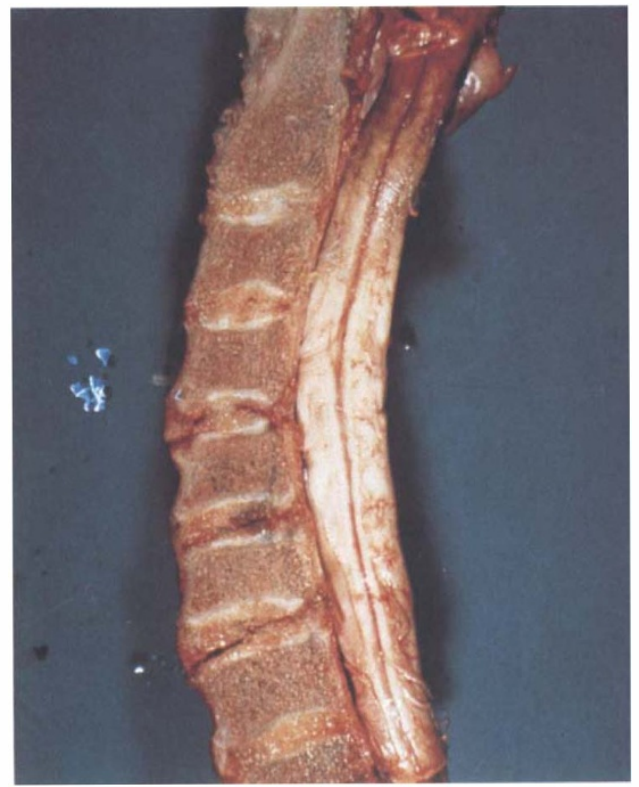

b

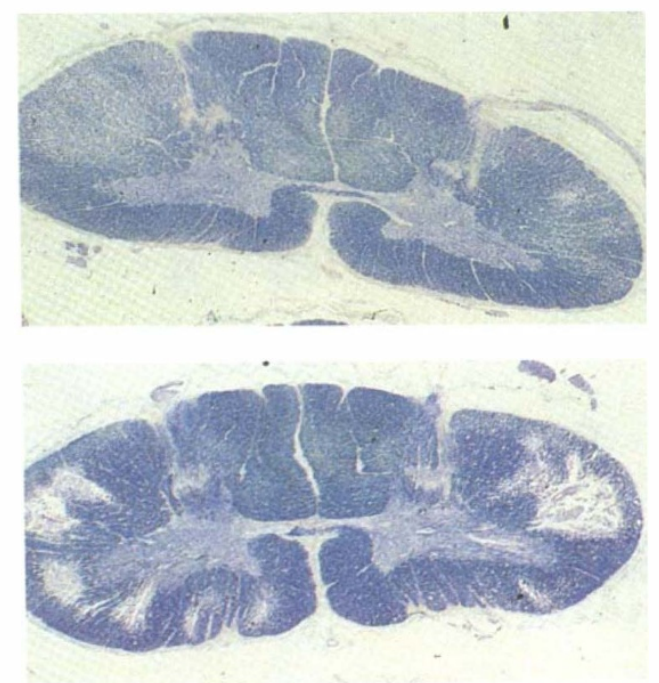

Figure 2 (a) Multiple rupture of the anterior ligaments and intervertebral discs, extensive swelling of the spinal cord. (b) The spinal cord at the level of C3-4-5 interspace. (c) The spinal cord at the C4-5 interspace. Loss of neurocytes in the grey matter and necrosis in the lateral tract on both sides and anterior tract on the right side. Position sensation was preserved.

that this occurred during life, thus accounting for the normal radiographic appearance.

\section{Case 9}

A 39 year old man fell from a $6 \mathrm{~m}$ precipice while under the influence of alcohol and sustained two large bruises on his frontoparietal region. He developed immediate tetraplegia below C5 and died 20 days later.

Roentgenograms revealed bilateral fracture of $\mathrm{C} 4$ neural arches between the superior and inferior articular processes and anterolisthesis of $\mathrm{C} 4$ vertebra one-half of the width of the vertebial body with posteroinferior marginal fracture (Fig 6a).

At autopsy, all the elements of the cervical spine except for the posterior longitudinal ligament were severed between $\mathrm{C} 4$ and $\mathrm{C} 5$ vertebrae and stability was completely impaired. The neural arch of $\mathrm{C} 4$ became an isolated fragment like a neural arch in spondylolisthesis and was connected with $\mathrm{C} 3$ and $\mathrm{C} 5$ neural arches by the ligamentum flavum. A fracture line was observed to run obliquely from the midpoint of the posterior margin of $\mathrm{C} 4$ vertebra through the intervertebral disc to the anterosuperior margin of C5. The upper segment of the spinal column was dislocated as if it were pushed forward. The triangular bone fragment detached from the posteroinferior margin of $\mathrm{C} 4$ and that from the anterosuperior margin of $\mathrm{C} 5$ both remained at their original anatomic position.

The posterior longitudinal ligament escaped rupture and was lifted from the posterior surface of C4. It was assumed that the spinal cord was stretched and contused widely by the fracture-dislocation. The parenchyma of $\mathrm{C} 3,4,5$ segments almost completely disappeared due to marked haemorrhage and colliquative necrosis. The haemorrhage extended above and below and into the grey matter. The length of this lesion was $10.5 \mathrm{~cm}$ (Fig 6b).

\section{Discussion}

Barnes $^{2}$ recognised two types of hyperextenion injuries of the cervical spine: (1) injury to an arthritic spine which occurs in patients more than 50 years of age and (2) posterior dislocation which occurs under 50 years of age. In this series, hyperextension 


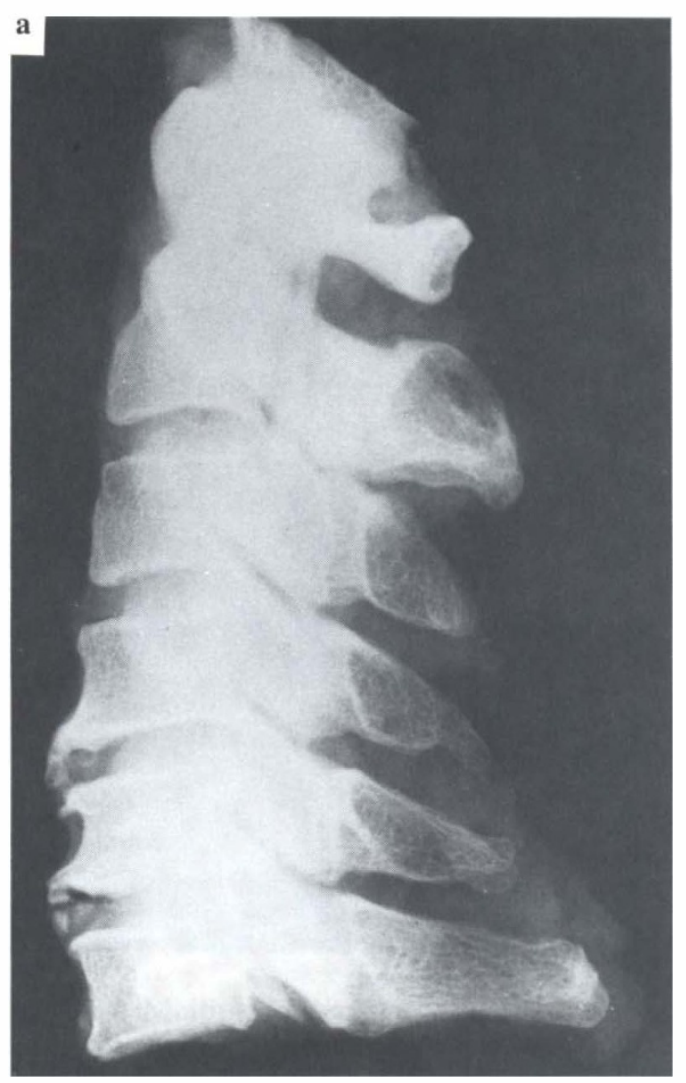

b

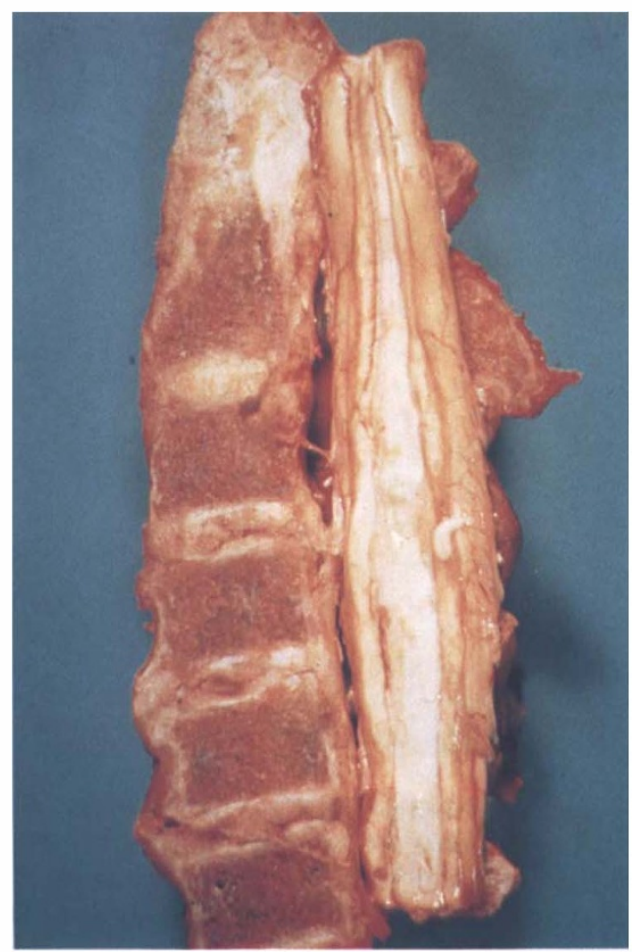

Figure 3 (a) Roentgenogram of moderate osteoarthritic change with fracture of osteophyte at the anterior lower margin of C6 vertebra. (b) Multiple rupture of the intervertebral discs. The spinal cord is remarkably swollen with small focal softening.

injuries to the arthritic spine were encountered in four patients over 64 years of age (cases 1, 2, 3, and 4). All cases showed no bone injury in the roentgenograms. Bedbrook $^{3}$ emphasised the multiplicity of the injury in hyperextension injury of the cervical spine. The anterior longitudinal ligaments and intervertebral discs of the illustrated cases were ruptured at two or three levels (Table I).

With regard to the mechanism of cord injury due to hyperextension injury of the arthritic cervical spine, according to Taylor ${ }^{4}$ the cord is trapped anteriorly by the osteophytes and posteriorly by the inward bulging of the ligamentum flavum, while Schneider ${ }^{5}$ claims that the cord is compressed or squeezed in several places, causing intramedullary haemorrhage giving rise to an acute central cervical spinal cord injury syndrome. Oedema over a length of the cord with small multiple focal softenings or necrosis in the central portion of the cord was observed and three out of four patients showed incomplete paralysis.

Guttmann ${ }^{6}$ described five cases of extension injury of ankylosing cervical spondylitis and suggested that the determining factor in the mechanism of extension injury to the spine is the rigidity of the vertebral column. Rigidity prevents flexion and rotation which is the most common mechanism in fracturedislocation of the spine in subjects without an ankylosed vertebral column. In this series, the rigidity of the cervical spine was due to ankylosing hyperostosis in two patients (cases 5 and 6) and to ossification of the posterior longitudinal ligament in one case (case 7). Injuries of the spine were at a single site and no bone injury was observed 


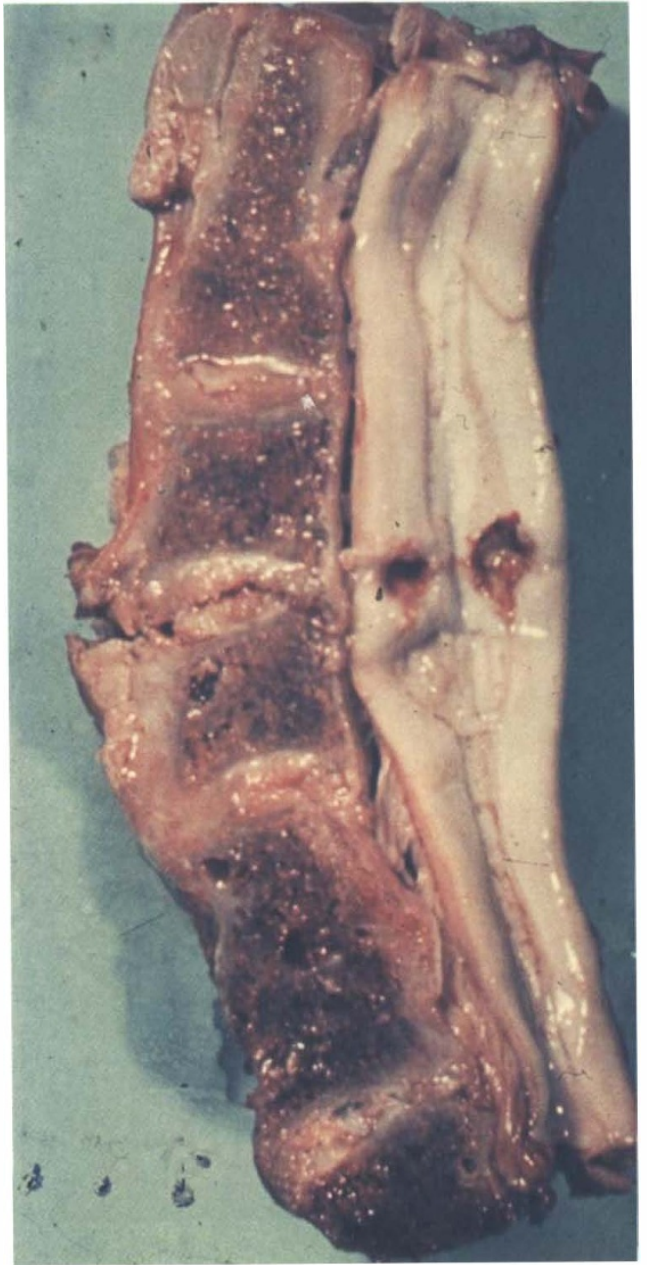

Figure 4 Hyperextension injury of the rigid cervical spine. The rupture occurred immediately above the ossified region. The spinal cord is extensively swollen with a small cavity in the central portion of the spinal cord.

on roentgenograms. The spinal cord was severely contused in case 5 and was constricted or compressed because of narrowing of the spinal canal (cases 6 and 7).

Case 8 shows posterior dislocation of the cervical spine with a normal roentgenogram. Taylor and Blackwood ${ }^{7}$ made a detailed report on an autopsy case of posterior dislocation between $\mathrm{C} 6$ and $\mathrm{C} 7$ vertebrae. The pathological findings of their case are similar to case 8 . Forsyth ${ }^{8}$ discussed the mechanism of this dislocation. When the

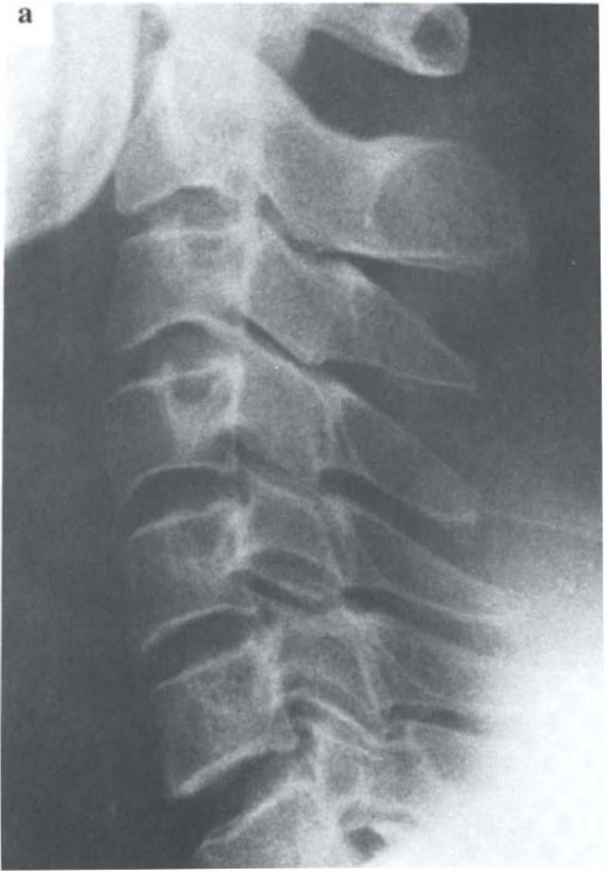

b c

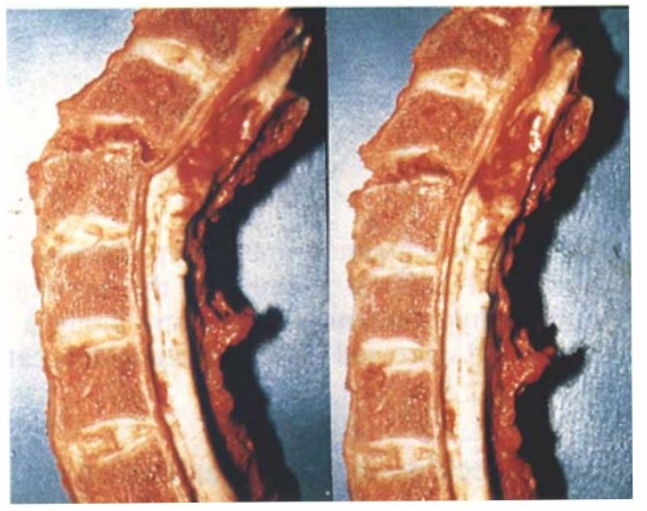

Figure 5 (a) Roentgenogram at the time of initial examination. (b) Sagittal section of the cervical spine in hyperextension. The anterior longitudinal ligament and the intervertebral disc are ruptured. The posterior longitudinal ligament is intact but is separated from the posterosuperior border of $\mathrm{C} 4$, thus allowing backward displacement. The spinal cord is momentarily contused between the posterior inferior border of $\mathrm{C} 3$ and the lamina of $\mathrm{C} 4$. (c) In the flexed position, the dislocation is completely reduced and the anatomical contours are restored. 

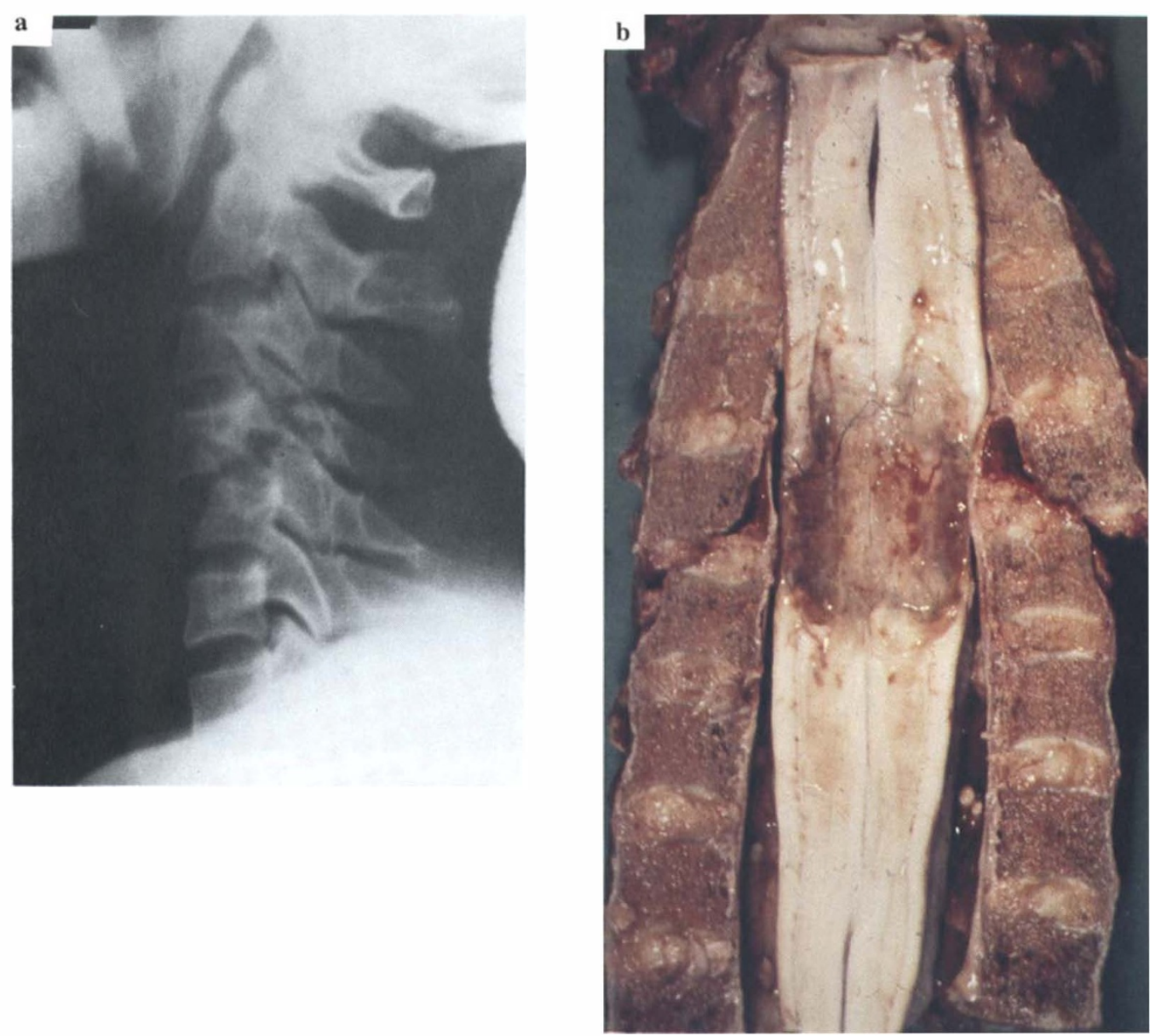

Figure 6 (a) Roentgenogram of hyperextension fracture-dislocation of the fourth and fifth cervical vertebra. (b) Sagittal section of the cervical spine and the spinal cord. The spinal column is severed by hyperextension travelling along a circular course. It is assumed that the spinal cord is stretched and contused by the fracture-dislocation.

head and neck go into hyperextension without any element of compression, the spinous and articular processes are forced together and act as a fulcrum, causing the longitudinal ligament to rupture. Separation then occurs between the cancellous bone of the vertebral body and adjacent cartilaginous endplate or between the endplate and the disc proper. The portion of the cervical spine above the separation continues backward, stripping the longitudinal ligament away from the vertebral body below, thus carrying the spinal cord backward against the sharp leading edge of the lamina of this lower vertebra and causing a contusion of the cord at this level. In this type of dislocation, there is nothing to prevent spontaneous reduction. This usually occurs to such a degree that subsequent roentgenograms appear normal.

Case 9 shows another type of extension injury of the cervical spine which shows a forward displacement. Therefore, Burke' called it hyperextension injury masquerading as flexion injury. Forsyth ${ }^{8}$ described the mechanism of this injury as follows. As the head and neck are forced into hyperextension, the head moves through an arc. 
Table I Hyperextension injuries

\begin{tabular}{|c|c|c|c|c|c|c|c|c|c|c|c|c|}
\hline \multirow{2}{*}{$\begin{array}{l}\text { Case } \\
\text { no. }\end{array}$} & \multirow[t]{2}{*}{ Age } & \multirow[t]{2}{*}{ Sex } & \multirow{2}{*}{$\begin{array}{l}\text { Cause of } \\
\text { injury }\end{array}$} & \multirow{2}{*}{$\begin{array}{l}\text { Roentgeno- } \\
\text { gram }\end{array}$} & \multirow{2}{*}{$\begin{array}{l}\text { Level and grade } \\
\text { of paralysis }\end{array}$} & \multirow{2}{*}{$\begin{array}{l}\text { Survival } \\
\text { time }\end{array}$} & \multicolumn{4}{|c|}{ Tissues involved } & \multirow[t]{2}{*}{ Macroscopic features } & \multirow{2}{*}{$\begin{array}{l}\text { Extent of } \\
\text { spinal cord } \\
\text { damage }\end{array}$} \\
\hline & & & & & & & ALL & PLL & ISL & Disc & & \\
\hline 1 & 75 & $\mathrm{M}$ & $\begin{array}{l}\text { Traffic } \\
\text { accident }\end{array}$ & $-a$ & C4 incomplete & 21 days & + & - & - & $\begin{array}{c}+ \\
3 \text { discs }\end{array}$ & $\begin{array}{l}\text { Multiple small focal } \\
\text { necrosis } \\
\text { Atrophy }\end{array}$ & Each $0.5 \mathrm{~cm}$ \\
\hline 2 & 70 & M & $\begin{array}{l}\text { Fall from } \\
\text { biycle }\end{array}$ & $-a$ & C5 complete & $5 \operatorname{mos}$ & + & - & - & + & $\begin{array}{l}\text { Disappearance of } \\
\text { parenchyma } \\
\text { Softening C4, C7 }\end{array}$ & $\begin{array}{r}2.5 \mathrm{~cm} \\
\text { Each } 1.0 \mathrm{~cm}\end{array}$ \\
\hline 3 & 73 & M & $\begin{array}{l}\text { Hit by } \\
\text { car }\end{array}$ & $-a$ & C7 incomplete & 27 days & $\begin{array}{c}+ \\
3 \text { places }\end{array}$ & - & - & $\begin{array}{c}+ \\
3 \text { discs }\end{array}$ & $\begin{array}{l}\text { Oedema with small focal } \\
\text { necrosis } \\
\text { Vacuolisation in the } \\
\text { lateral column }\end{array}$ & $7.0 \mathrm{~cm}$ \\
\hline 4 & 64 & M & Fall $2.5 \mathrm{~m}$ & $\begin{array}{c}{ }^{\mathrm{a}} \\
\text { Detached } \\
\text { osteophyte }\end{array}$ & C5 incomplete & 26 days & $\begin{array}{c}+ \\
2 \text { places }\end{array}$ & - & - & $\begin{array}{c}+ \\
3 \text { discs }\end{array}$ & $\begin{array}{l}\text { Oedema with small focal } \\
\text { necrosis }\end{array}$ & $7.0 \mathrm{~cm}$ \\
\hline 5 & 77 & $\mathrm{M}$ & Fall $4.0 \mathrm{~m}$ & $-\mathrm{b}$ & C5 complete & 9 days & + & - & - & + & $\begin{array}{l}\text { Small cavity with } \\
\text { haemorrhage } \\
\text { Oedema }\end{array}$ & $0.5 \mathrm{~cm}$ \\
\hline 6 & 61 & M & Fall $2.0 \mathrm{~m}$ & $-b$ & C5 complete & $18 \mathrm{mos}$ & + & - & - & + & $\begin{array}{l}\text { Disappearance of } \\
\text { parenchyma } \\
\text { Atrophy }\end{array}$ & $7.0 \mathrm{~cm}$ \\
\hline 7 & 53 & $\mathrm{~F}$ & $\begin{array}{l}\text { Fall onto } \\
\text { face }\end{array}$ & $-c$ & C5 incomplete & $2 \operatorname{mos}$ & + & - & - & $2 \stackrel{+}{2 \text { discs }}$ & $\begin{array}{l}\text { Oedema } \\
\text { Small cavity }\end{array}$ & $\begin{array}{l}5.0 \mathrm{~cm} \\
0.5 \mathrm{~cm}\end{array}$ \\
\hline 8 & 34 & $\mathrm{M}$ & $\begin{array}{l}\text { Thrown into } \\
\text { river } 2.5 \mathrm{~m}\end{array}$ & - & C5 complete & 6 days & + & - & - & + & Haemorrhagic necrosis & $3.0 \mathrm{~cm}$ \\
\hline 9 & 39 & $\mathrm{M}$ & Fall $6.0 \mathrm{~m}$ & $\begin{array}{c}+ \\
\text { Fracture } \\
\text { dislocation }\end{array}$ & C5 complete & 20 days & + & - & + & + & $\begin{array}{l}\text { Haemorrhagic necrosis } \\
\text { Haemorrhage in grey } \\
\text { matter }\end{array}$ & $10.5 \mathrm{~cm}$ \\
\hline
\end{tabular}


The hyperextension force is first directed backward and then downward, and, if allowed to continue, it will finally be travelling in a forward direction. When the neck goes into hyperextension, the relatively inelastic anterior longitudinal ligament may rupture. As the anterior longitudinal ligament does not rupture until very late in the brief span of time when the hyperextension force is acting, the force acts on the downward segment of its arc and is transmitted to the articular process. The articular processes or pedicles are compressed and fractured, and the hyperextension force is still acting in a downward and now somewhat forward direction. The force can now actually push the body of the vertebra forward, since the effectiveness of the articular processes in preventing this type of displacement has been eliminated.

The characteristic findings on roentgeno- grams after hyperextension fracture-dislocation are anterior displacement of the fractured vertebra to a mild or moderate degree, multiple small fractures of the posterior bone elements, and sometimes the characteristic little chip of bone pulled away from the anterior inferior margin of the body of the displaced vertebra. The fractures of the posterior bone elements usually consist of upward compression or displacement of the inferior articular process of the vertebra above.

The pathological findings of case 9 demonstrate clearly that the mechanism of this injury postulated by Forsyth ${ }^{8}$ is quite correct. Roentgenograms of case 9 also show the same findings as were described by Forsyth.

It must be noted that in every patient the anterior longitudinal ligament was found to be disrupted.

\section{References}

1 Kinoshita H (1993) Pathology of cervical intervertebral disc injuries. Paraplegia 31: 553-559.

2 Barnes R (1948) Paraplegia in cervical spinal injuries. J Bone Joint Surg 30B: 234-244.

3 Bedbrook GM (1977) Compression, flexion and extension injuries of the cervical spine with tetraplegia. Proceedings of Nineteenth Veterans Administration Spinal Cord Injury Conference, Scottsdale, Arizona: 16-23.

4 Taylor AR (1951) The mechanism of injury to the spinal cord in the neck without damage to the vertebral column. J Bone Joint Surg 33B: 543-547.

5 Schneider RC, Thompson JM, Rebin J (1958) The syndrome of acute central cervical spinal cord injury. J Neurol Neurosurg Psychiatry 21: 216-227.

6 Guttmann L (1966) Traumatic paraplegia and tetraplegia in ankylosing spondylitis. Paraplegia 4: 188-201.

7 Taylor AR, Blackwood W (1948) Paraplegia in hyperextension cervical injuries with normal radiographic appearances. J Bone Joint Surg 30B: 245-248.

8 Forsyth HF (1964) Extension injuries of the cervical spine. J Bone Joint Surg 46A: 1702-1097.

9 Burke DC (1971) Hyperextension injuries of the spine. J Bone Joint Surg 53B: 3-12. 